CZASOPISMO INŻYNIERII LĄDOWEJ, ŚRODOWISKA I ARCHITEKTURY JOURNAL OF CIVIL ENGINEERING, ENVIRONMENT AND ARCHITECTURE

JCEEA, t. XXXIII, z. 63 (3/16), lipiec-wrzesień 2016, s. 139-149

Galina KALDA ${ }^{1}$

Beata KOCZERA ${ }^{2}$

\title{
ANALIZA ZANIECZYSZCZENIA WÓD POWIERZCHNIOWYCH I PODZIEMNYCH ZAKŁADAMI PRZEMYSŁOWYMI NA PODKARPACIU
}

\begin{abstract}
$\mathrm{W}$ artykule prezentowano analizę problematyki, związanej $\mathrm{z}$ ochroną wód powierzchniowych i podziemnych przed zanieczyszczeniami, jakie mają pochodzenie od zakładów przemysłowych na terenie województwa podkarpackiego. Największym problemem gospodarki wodnej jest zanieczyszczenie wód powierzchniowych, głównie rzecznych. Przyczyną tego są głównie zrzuty ścieków przemysłowych i komunalnych, oraz wypłukiwanie nawozów sztucznych. W województwie podkarpackim występuje kilka dużych zakładów przemysłowych, w których stosowana technologia przyczynia się do powstawania zanieczyszczeń, głównie wody powierzchniowej. Fabryki posiadają specjalną technologię oczyszczania ścieków przemysłowych, aby zniwelować do odpowiedniego stopnia zawartość metali ciężkich, siarczanów, chlorków, węglowodorów, fenoli oraz innych zanieczyszczeń organicznych i nieorganicznych. Zrzut ścieków do wody wiąże się ze zmianą jej właściwości oraz oddziaływaniem na faunę i florę. Następnie w procesie samooczyszczania dochodzi do rozkładu zanieczyszczeń. Województwo podkarpackie posiada zasoby wód słodkich w postaci rzek, jezior oraz wód głębinowych. Ich ilość jest zależna od sposobu jej wykorzystania, położenia geograficznego, klimatu. Na podstawie analizy stanu wód powierzchniowych i podziemnych i na przykładzie zanieczyszczenia wód wybranymi firmami pokazano, że sytuacja wód powierzchniowych jest w dość złym stanie. Wody te są nie dobrej czystości, a niekiedy nie spełniają żadnych wymogów i stanowią wody pozaklasowe. Związane jest to $\mathrm{z}$ rozwojem gospodarczym oraz wprowadzeniem do nich ścieków komunalnych i przemysłowych. Ścieki powstałe w fabrykach są poddawane odpowiednim procesom oczyszczania, gdyż nie wystąpiło przekroczenie dopuszczalnych norm. W celu dalszego zmniejszenia poszczególnych wartości należałoby zastanowić się nad unowocześnieniem technologii stosowanych przy oczyszczaniu danych ścieków lub np. zwiększenie czasu przebywania w osadnikach w celu zmniejszenia ilości zawiesiny ogólnej.
\end{abstract}

Słowa kluczowe: ochrona, wody podziemne, wody powierzchniowe, zanieczyszczenie, zakłady przemysłowe

\footnotetext{
${ }^{1}$ Autor do korespondencji / corresponding author: Galina Kalda, Politechnika Rzeszowska, 35-959 Rzeszów, ul. Powstańców Warszawy 6, tel. +48 17 8651068, kaldagal@prz.edu.pl

${ }^{2}$ Beata Koczera, Politechnika Rzeszowska
} 


\section{Wprowadzenie}

Polska należy do krajów gdzie zasoby wody są zróżnicowane i zmienne $\mathrm{w}$ czasie oraz przestrzeni. Związane jest to nie tylko z ukształtowaniem terenu, ale również z częstotliwością występowania opadów, temperatury oraz infiltracją wód podziemnych. Głównymi konsumentami wody są energetyka cieplna, przemysł, rolnictwo, leśnictwo i gospodarka komunalna. Natomiast użytkownikami wody są żegluga, turystyka i rekreacja oraz energetyka cieplna. Największe zużycie wody powodują zakłady energetyczne, hutnictwo, przemysł spożywczy, chemiczny, papierniczy oraz metalurgiczny.

Największym problemem gospodarki wodnej jest zanieczyszczenie wód powierzchniowych, głównie rzecznych. Przyczyną tego są głównie zrzuty ścieków przemysłowych i komunalnych, oraz wypłukiwanie nawozów sztucznych. W województwie podkarpackim występuje kilka dużych zakładów przemysłowych, w których stosowana technologia przyczynia się do powstawania zanieczyszczeń, głównie wody powierzchniowej. Fabryki posiadają specjalną technologię oczyszczania ścieków przemysłowych, aby zniwelować do odpowiedniego stopnia zawartość metali ciężkich, siarczanów, chlorków, węglowodorów, fenoli oraz innych zanieczyszczeń organicznych i nieorganicznych. Zrzut ścieków do wody wiąże się ze zmianą jej właściwości oraz oddziaływaniem na faunę i florę. Następnie w procesie samooczyszczania dochodzi do rozkładu zanieczyszczeń.

Województwo podkarpackie posiada zasoby wód słodkich w postaci rzek, jezior oraz wód głębinowych. Ich ilość jest zależna od sposobu jej wykorzystania, położenia geograficznego, klimatu.

\section{Zanieczyszczenia i zagrożenia wód na terenie województwa podkarpackiego}

Powstawanie nowych gałęzi przemysłu sprzyja zanieczyszczeniom wód naturalnych. Źródła zanieczyszczeń możemy podzielić na:

- punktowe - to zasolone wody kopalniane, ścieki z systemów kanalizacyjnych i podgrzane wody chłodnicze;

- obszarowe - są to zanieczyszczenia z atmosfery, które przedostają się do wód, odpływy ze składowisk odpadów, terenów rolniczych i przemysłowych, zanieczyszczenia pasmowe wzdłuż tras komunikacyjnych [1].

Ścieki pochodzące z systemów kanalizacyjnych są głównie przyczyną zanieczyszczeń wód powierzchniowych. Wyróżniamy:

- ścieki bytowo-gospodarcze, pochodzące z gospodarstw domowych, zakładów pracy oraz użyteczności publicznej, w których woda została zużyta do celów higienicznych;

- ścieki przemysłowe - są to wody, które zostały zużyte w wyniku procesów technologicznych; 
- ścieki opadowe - są to głównie wody pochodzące z roztopów oraz opadów atmosferycznych;

- ścieki filtracyjne - są to wody, które dostają się do kanalizacji z gruntu.

Ścieki bytowo-gospodarcze charakteryzują się stałym składem wynikającą z powtarzalności wykonywania zabiegów higienicznych. Ścieki przemysłowe uzależnione są od rodzaju przemysłu, technologii oraz materiałów wykorzystywanych w zakładzie. Ścieki opadowe i infiltracyjne charakteryzują się niskim stężeniem zanieczyszczeń [2].

Województwo podkarpackie w ostatnich latach rozwija się gospodarczo. Występują tam nie tylko małe lokalne zakłady przemysłowe, ale również duże fabryki mające istotne znaczenie ekonomiczne w skali kraju i świata. Wywiera to zasadniczy wpływ nie tylko na życie i rozwój społeczno-gospodarczy ale również stwarza zagrożenia dla środowiska. Głównie rozwinęły się sektory przetwórstwa rolno-spożywczego i przemysłu chemicznego w miastach Sanok, Tarnobrzeg, Jasło, Dębica i Nowa Sarzyna, oraz przemysłu elektromaszynowego w Rzeszowie, Krośnie, Mielcu, Sanoku i Stalowej Woli [3-6].

Sanockie Zakłady Przemysłu Gumowego STOMIL SANOK S. A. zlokalizowane są w Sanoku po obu stronach Sanu. Przedsiębiorstwo zajmuje się wyrobami gumowymi i gumowo-metalowymi dla potrzeb przemysłu motoryzacyjnego, farmaceutycznego, maszynowego, budownictwa oraz sprzętu AGD. Dopuszczalna wartość emisji ścieków została określona kolektorami lewobrzeżnym i prawobrzeżnym do rzeki San.

Zostały również określone miejsca zrzutu ścieków oraz monitoring odprowadzanych ścieków. Pracownicy zakładu co dwa miesiące kontrolują wskaźniki $\mathrm{BZT}_{5}$, CHZT, pH, zawiesiny ogólne, azot amonowy, azot ogólny, azot azotynowy, węglowodory ropopochodne oraz substancje ekstrahujące się eterem naftowym.

Wytwórnia Sprzętu Komunikacyjnego „PZL-Rzeszów” S.A. zajmuje się produkcją różnych elementów lotniczych oraz jednostek napędowych. Zakład posiada własną oczyszczalnię ścieków. Szczególnie niebezpieczne ścieki pogalwaniczne oczyszczane są za pomocą odwróconej osmozy, wymienników jonitowych oraz destylacji próżniowej. Co najmniej dwa razy w roku muszą być przeprowadzane badania wpływu instalacji na wody podziemne, w których sprawdzone będzie $\mathrm{pH}$, amoniak, azotyny, azotany, chlorki, przewodność elektryczną, fluorki, siarczany, żelazo, mangan, cyjanki, glin, ogólny węgiel organiczny, węglowodory chlorowane oraz poziom zwierciadła wód podziemnych.

Firma Oponiarska Dębica S. A. zajmuje się produkcją opon samochodowych dla wszelkich rodzajów pojazdów. Firma jest największym zakładem pracy w województwie podkarpackim.

Systematycznie powinny być przeprowadzane pomiary wskaźników z częstotliwością przynajmniej raz na dobę. Pomiar aldryny i heksachlorocykloheksanu należy przeprowadzać z równoczesnym pomiarem wody powierzchniowej [7]. 
ICN Polfa Rzeszów S.A. stanowi fragment międzynarodowego koncernu farmaceutycznego. Zajmują się produkcją leków oraz ochroną zdrowia ludzi na całym świecie. Cechują się wysoką jakością produktów, odpowiedzialnością oraz świadczeniem usług wedle potrzeb klienta [8].

„SANWIL” S.A. w Przemyślu zajmuje się produkcją materiałów tapicerskich dla krzeseł, foteli i sof. Przeprowadzają produkcję materiałów obiciowych typu skay, polstram, plawil, skiltex [9]. Pomiar jakości ścieków prowadzony jest w układzie miesięcznym.

\section{Analiza i wyniki zanieczyszczeń pochodzących od zakładów przemysłowych na terenie województwa podkarpackiego}

Lata 2009-2013 charakteryzuja się tendencją spadkową związaną z produkcją ścieków przemysłowych wymagającą oczyszczania.

Największa produkcja ścieków przemysłowych znajduje się w okolicach Tarnobrzegu, Rzeszowa, Dębicy, Stalowej Woli, Jasła, Mielca i Jedlicza. Zlokalizowane są tam największe i najbardziej znaczące zakłady przemysłowe w województwie. W 2013 r. jedynie w Dębicy wystąpił wzrost ścieków, w pozostałych miastach nastąpiło zmniejszenie wytworzonych ścieków. Największy spadek odnotowano w okolicach Tarnobrzegu, w porównaniu z 2009 r., gdzie produkcja ścieków była największa, róznica wynosi $7400 \mathrm{~m}^{3}$ ścieków oczyszczonych. Przyczyną było zaprzestanie odprowadzania wód zasolonych przez Kopalnię Siarki „Machów” S.A.

$\mathrm{Na}$ terenie województwa podkarpackiego znajduje się 31 zakład przemysłowy, które są wyposażone w własną oczyszczalnię ścieków [10].

\subsection{Analiza ścieków przemysłowych w Sanockich Zakładach Przemysłu Gumowego „STOMIL SANOK” S.A.}

Na rys. 1-3 pokazane zależności ilości zanieczyszczeń w ściekach przemysłowych od wartości granicznej.

Wartość wskaźnika nie została przekroczona, co świadczy o odpowiednim oczyszczaniu ścieków przemysłowych. Wzrost odnotowany w ostatnich latach związany jest z większą produkcją materiałów gumowych.

Wartości normatywne nie zostały przekroczone. Ścieki przemysłowe zawierają niski poziom danego parametru. Odpowiednio oczyszczone nie stanowią zagrożenia dla odbiornika.

Chemiczne zapotrzebowanie na tlen mieści się w wartościach dopuszczonych przez wojewodę podkarpackiego w pozwoleniu zintegrowanym. 

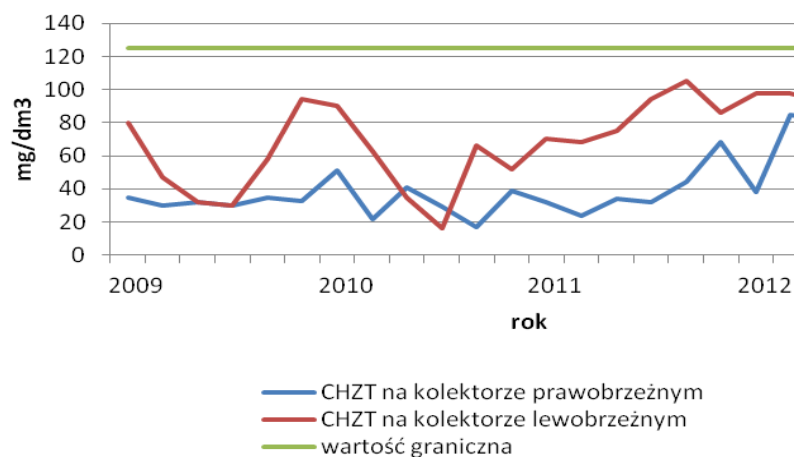

Rys. 1. Zależność wskaźnika CHZT od wartości granicznej [3-6]

Fig. 1. Dependence of rate COD from the limit value [3-6]

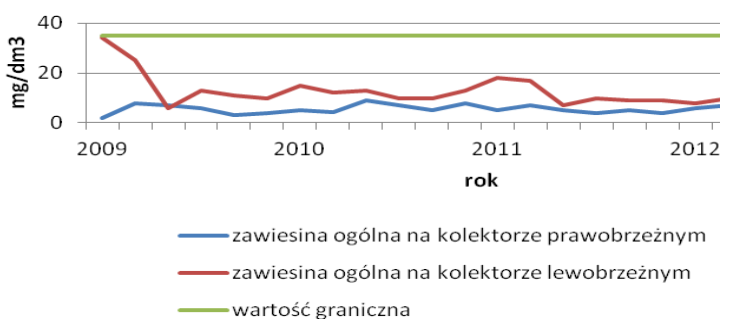

Rys. 2. Zależność zawiesiny ogólnej w okresie bezdeszczowym od wartości granicznej [3-6]

Fig. 2. Dependence of suspended matter in the rainless period from the limit value [3-6]

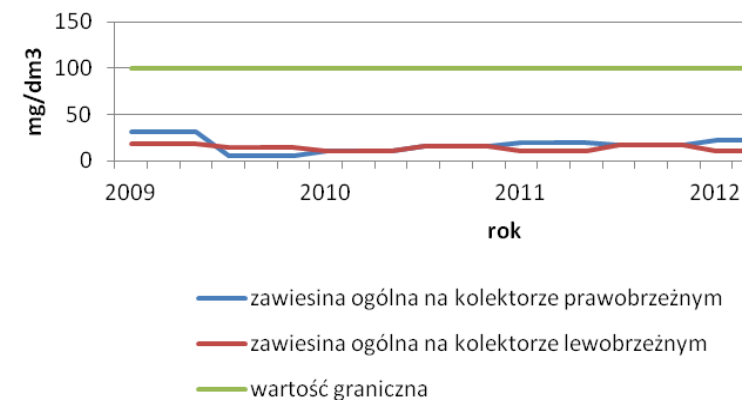

Rys. 3. Zależność zawiesiny ogólnej w okresie deszczowym od wartości granicznej [3-6]

Fig. 3. Dependence of suspended matter in the rainy period from the limit value [3-6] 


\subsection{Analiza ścieków przemysłowych w Wytwórni Sprzętu Komunikacyjnego „PZL-Rzeszów” S.A.}

Analizując wyniki scieków cyjankowych w Wytwórni Sprzętu Komunikacyjnego „PZL-Rzeszów” S.A. nie zauważamy żadnych przekroczeń wartości dopuszczalnych. Na rys. 4-6 przedstawiono wyniki pomiarów.

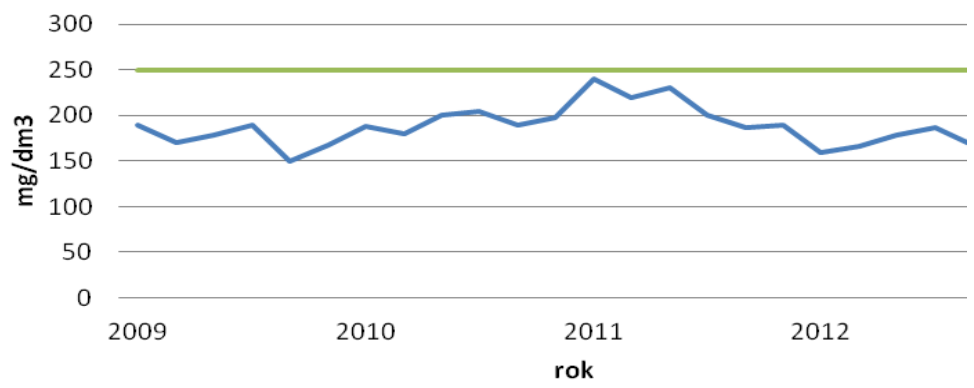

— wartość CHZT w kolejnych pomiarch ——wartosć graniczna $\mathrm{CHZT}$

Rys. 4. Zależność wskaźnika CHZT od wartości dopuszczalnej [3-6]

Fig. 4. Dependence of rate COD from the permissible value [3-6]

Jak widać na rys. 4, wartrość CHZT w odprowadzanych ściekach nie przekraczała wartości dopuszczalnej. Na początku 2011 r. nastąpił niewielki wzrost zaś następnie wartości malały.

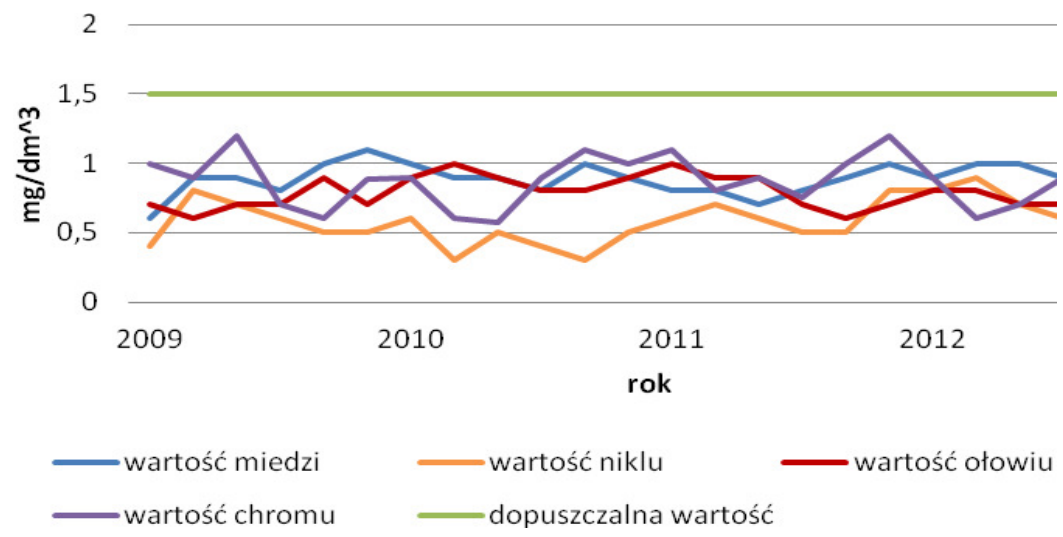

Rys. 5. Zależność miedzi, niklu, ołowiu i chromu od wartości dopuszczalnej [3-6]

Fig. 5. Dependence of copper, nickel, lead and chromium from the permissible value [3-6] 
Na rys. 5. zauważyć można, że wartości metali ciężkich utrzymywały się na podobnej granicy. Żadna $\mathrm{z}$ danych nie przekroczyła wartości dopuszczonej w pozwoleniu zintegrowanym.

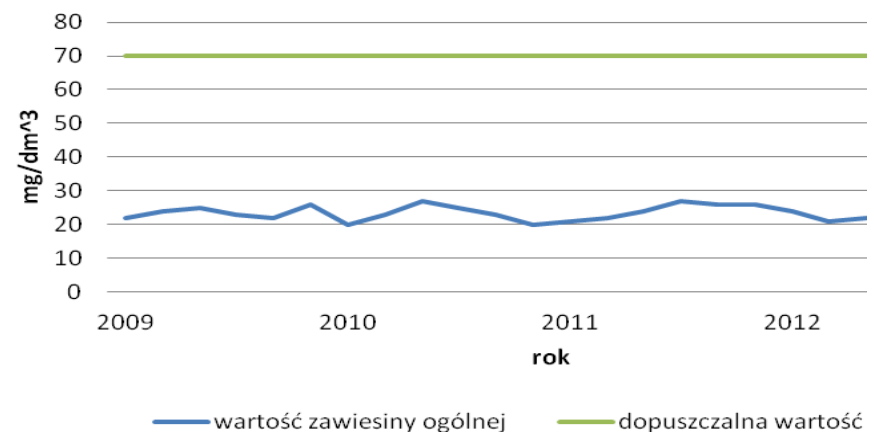

Rys. 6. Zależność zawiesiny ogólnej od wartości dopuszczalnej [3-6]

Fig. 6. Dependence of suspended matter from the permissible value [3-6]

Zawiesina ogólna utrzymywała się na stałym poziomie, dalekim od dopuszczalnego. Technologia stosowana w zakładzie pozwala na odpowiednie oczyszczenie ścieków.

\subsection{Analiza ścieków przemysłowych w Firmie Oponiarskiej Dębica S.A.}

Rys. 7-9 przedstawiają dopuszczalne wartości oraz wartości otrzymywane z pomiarów uśrednione do miesiąca dla Firmy Oponiarskiej Dębica S.A.

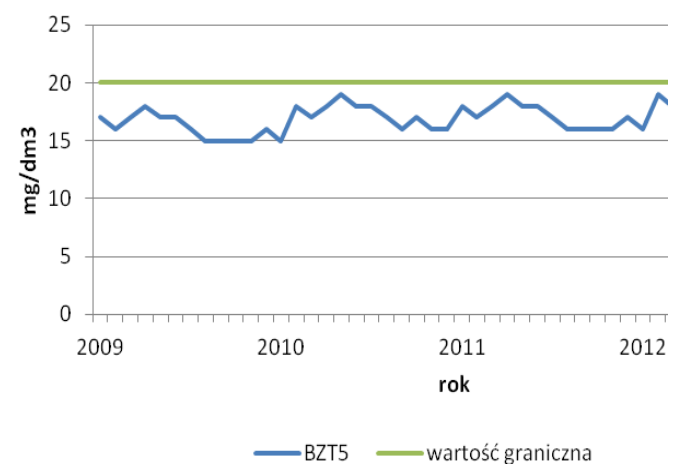

Rys. 7. Zależność wskaźnika BZT5 od wartości dopuszczalnej [3-6]

Fig. 7. Dependence of rate BOD5 from the permissible value [3-6]

Firma Oponiarska w Dębicy nie wykazała przekroczeń dla BZT $\mathrm{B}_{5}$ W połowie 2012 r. wartości te były zbliżone do wartości dopuszczalnej jednak nie została ona przekroczona. Następnie w kolejnych miesiącach odnotowano spadek. 


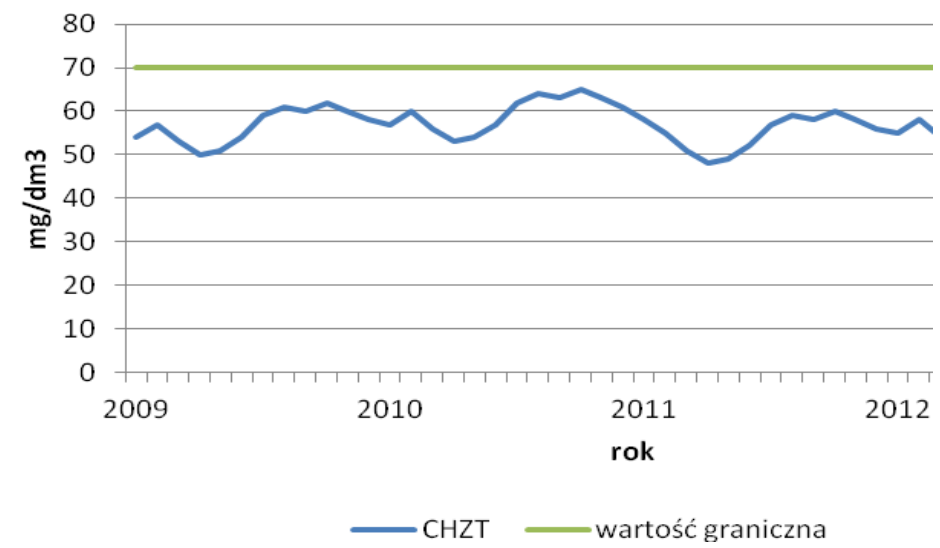

Rys. 8. Zależność CHZT od wartości dopuszczalnej [3-6]

Fig. 8. Dependence of rate COD from the permissible value [3-6]

Dla parametru jakim jest chemiczne zapotrzebowanie na tlen nie wykazano przekroczeń dopuszczalnej wartości. Ścieki przemysłowe powstałe w firmie oponiarskiej są dostatecznie oczyszczane.

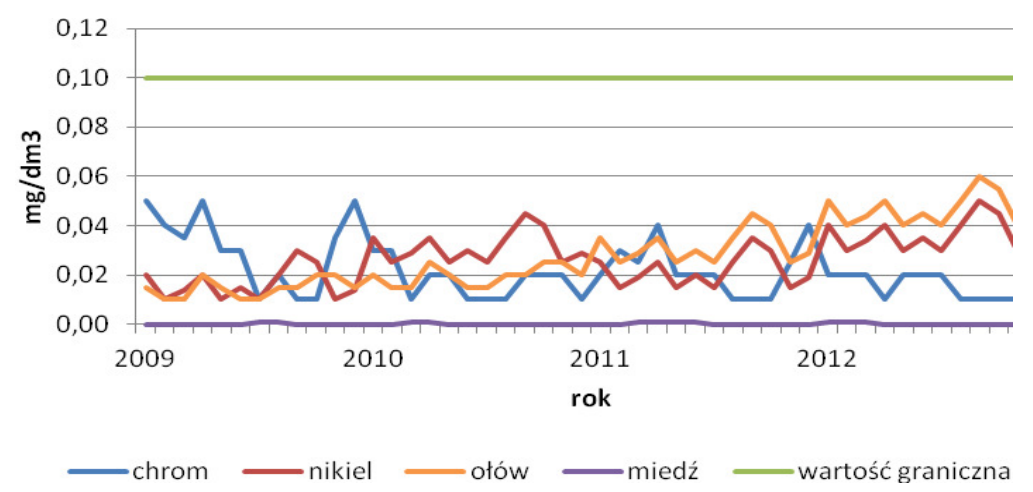

Rys. 9. Zależność chromu, niklu, ołowiu, i miedzi od wartości granicznej [3-6]

Fig. 9. Dependence of chromium, nickel, lead and copper from the permissible value [3-6]

Metale ciężkie powstające przy produkcji i obróbce gumy zostały odpowiednio zneutralizowane ze ścieków tak, że nie stanowią zagrożenia dla środowiska, a ich wartość nie przekracza $0,1 \mathrm{mg} / \mathrm{dm}^{3}$ ścieków.

Rys. 10 obrazuje skokowe zmiany parametru $\mathrm{BZT}_{5} \mathrm{~W}$ ściekach poddanych oczyszczeniu. Właściwości te wiążą się z wykonywaną technologią w zakładzie farmaceutycznym. 


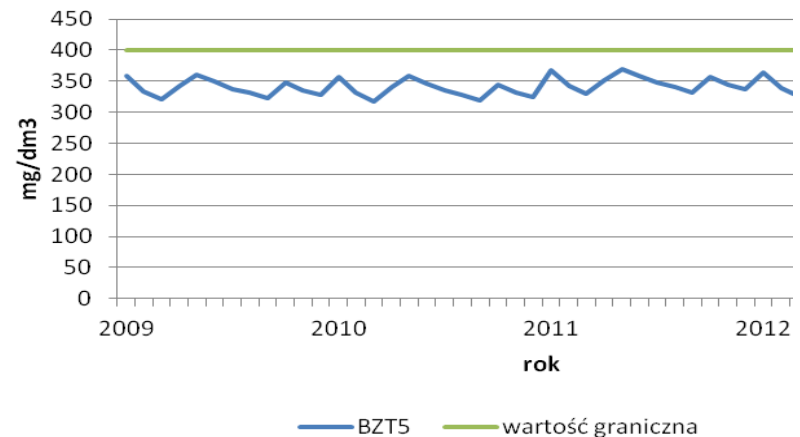

Rys. 10. Zależność wartości BZT5 od wartości dopuszczalnej [3-6]

Fig. 10. Dependence of rate BOD5 from the permissible value [3-6]

Wartości CHZT utrzymują się na stałym poziomie a jej ilość nie przekracza wartości dopuszczalnej w pozwoleniu zintegrowanym. Ścieki przemysłowe zatem są odpowiednio poddawane oczyszczaniu (rys. 11).

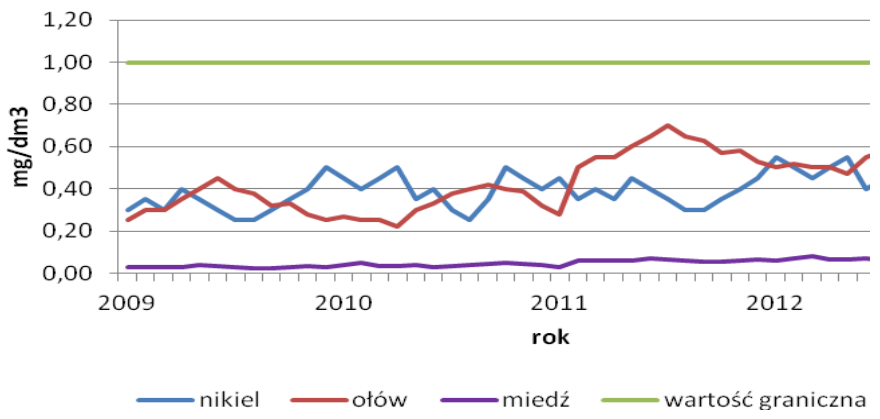

Rys. 11. Zależność niklu, ołowiu i miedzi od wartości dopuszczalnej [3-6]

Fig. 11. Dependence of nickel, lead and copper from the permissible value [3-6]

Zawartość miedzi w ściekach oczyszczonych jest bliska zeru. Ilość niklu i ołowiu jest nieco wyższa i zmienna na przestrzeni lat. W 2009-2010 rr. wartości te były mniejsze zaś od 2011 roku wzrastały. We wszystkich innych parametrach nie odnotowano przekroczeń, a ich wartości utrzymywały się na stałym poziomie.

\section{Podsumowanie}

Co stosuje się Podkarpacia, to sytuacja wód powierzchniowych jest w dość złym stanie. Wody te są nie dobrej czystości, a niekiedy nie spełniają żadnych wymogów i stanowią wody pozaklasowe. Związane jest to z rozwojem gospodarczym oraz wprowadzeniem do nich ścieków komunalnych i przemysłowych. 
Ścieki powstałe $\mathrm{w}$ fabrykach są poddawane odpowiednim procesom oczyszczania, gdyż nie wystąpiło przekroczenie dopuszczalnych norm. W celu dalszego zmniejszenia poszczególnych wartości należałoby zastanowić się nad unowocześnieniem technologii stosowanych przy oczyszczaniu danych ścieków lub np. zwiększenie czasu przebywania w osadnikach w celu zmniejszenia ilości zawiesiny ogólnej, CHZT oraz $\mathrm{BZT}_{5}$.

Najwięcej ścieków wyprodukowała Firma Oponiarska w Dębicy. Ścieki te charakteryzują się znaczną zawartością metali ciężkich takich jak: ołów, miedź, nikiel i chrom. Związane jest to z produkcją, jaka odbywa się w fabryce. W celu ich usunięcia przed wprowadzeniem do zlewni stosuje się zbiorniki retencyjny, osadnik trójkomorowy wraz z mechanicznym zgarniaczem osadów. Oczyszczone ścieki kierowane są do rzeki Wisłoki.

Zawartością metali ciężkich charakteryzują się również ścieki w Wytworni Sprzętu Komunikacyjnego „PZL-Rzeszów” S.A. Wyniki nie przekroczyły dopuszczalnej normy jednak ich zawartość znacząco wpływa na jakość rzeki Wisłok. Najnowsze technologie, jakie zostały zastosowane w oczyszczalni ścieków, pozwalają na znaczne ich usuniecie. Urządzenia takie jak wymienniki jonitowe, urządzenia do odwróconej osmozy oraz urządzenia do destylacji próżniowej i utlenianie ścieków cyjankowych pozwalają na ograniczenie emisji ładunku w ściekach.

Fabryka „SANWIL” S.A. w Przemyślu charakteryzuje się znaczną zawartością w ściekach zawiesiny ogólnej. Wartości te są bliskie $400 \mathrm{mg} / \mathrm{dm}^{3}$. Wyniki nie przekroczyły wartości normatywnych jednak ich ilość stwarza poważne zagrożenie dla rzeki San. Ważny jest prawidłowy monitoring ścieków zgodny z obowiązującymi normami i metodykami oraz ich rejestracja a także przechowywanie.

Analizowane ścieki z fabryki ICN Polfa Rzeszów S.A. charakteryzowały się znaczną ilością siarczanów i chlorków. Związane jest to z produkcją leków i używanych tam składników chemicznych. W przepisach szczególnych zakładu opisano metodykę wykonywania pomiarów ścieków przemysłowych.

\section{Literatura}

[1] Corbitt R.A.: „Standard handbook of environmental engineering”; McGRAW-HILL; 2012, s. 205-356.

[2] Neverova-Dziopak E.: „Ekologiczne aspekty ochrony wód powierzchniowych”, Oficyna Wydawnicza Politechniki Rzeszowskiej, Rzeszów 2007, s. 7-22.

[3] Wojewódzki Inspektorat Ochrony Środowiska: Raport o stanie środowiska w województwie podkarpackim w 2009 r., 2010, s. 48-79.

[4] Wojewódzki Inspektorat Ochrony Środowiska: Raport o stanie środowiska w województwie podkarpackim w 2010 r., 2011, s. 35-84.

[5] Wojewódzki Inspektorat Ochrony Środowiska: Raport o stanie środowiska w województwie podkarpackim w 2011 r., 2012, s. 32-75. 
[6] Wojewódzki Inspektorat Ochrony Środowiska: Raport o stanie środowiska w województwie podkarpackim w 2012 r., 2013, s. 52-107.

[7] Wojewódzki Inspektorat Ochrony Środowiska: Pozwolenie zintegrowane dla Firmy Oponiarskiej Dębica S.A., Rzeszów, 2006.

[8] Dymaczewski Z., Jeż-Walkowiak J.: „Water supply and water guality”, Poznań: Polskie Zrzeszenie Inżynierów i Techników Sanitarnych. Oddział Wielkopolski, 2012, s. 27-533.

[9] Wojewódzki Inspektorat Ochrony Środowiska: Pozwolenie zintegrowane dla „SANWIL” S.A. w Przemyślu., Rzeszów, 2007.

[10] Rak J., Boryczko K.: Metoda oceny zagrożenia ujęć wód podziemnych, Aktualne zagadnienia w uzdatnianiu i dystrybucji wody, red. I. Zimoch, W. Sawiniak, Politechnika Śląska, Instytut Inżynierii Wody i Ścieków, Gliwice, 2013, s. 147-155.

\section{THE PRINCIPLE OF THE PROTECTION OF SURFACE WATER AND GROUNDWATER AGAINST POLLUTION FROM INDUSTRIAL PLANTS IN THE CARPATHIAN}

\section{S u m m a r y}

In this article presents analysis of the issues associated with the protection of surface water and groundwater against pollution, to the origin of industrial establishments in the Carpathian province. The biggest is water pollution of surface water, mainly rivers. The reason for this is mainly industrial and municipal waste water discharges and leaching of fertilizers. In the Carpathian province there are several large industrial establishments, in which the applied technology contributes to the formation of pollutants, mainly surface water. The factory having a special industrial waste-water treatment technology to reduce to the desired degree of the content of heavy metals, sulphates, chlorides, hydrocarbons, phenols and other organic and inorganic pollutants. The discharge of sewage into the water is associated with a change in its properties and effects on fauna and flora. Then in the process of self-cleaning comes to the distribution of pollutants. The Carpathian province has freshwater resources in the from of rivers, lakes and deep waters. Their quantity is dependent on how it is used, geographic location, climate. On the basis of an analysis of the status of surface water and groundwater and the example of water pollution selected companies shows that the situation of surface water is in quite poor condition. These waters are not good, and sometimes do not meet any of the requirements and are outside of class water. This is connected with economic development and an introduction to municipal and industrial waste water. Waste water arising in factories are subject to the appropriate processes, because it does not limit exceedance of standards. In order to further reduce the individual values would consider revising technology used when cleaning or data eg. Increasing time reside in the inhabitants in order to reduce the amount of suspended matter.

Keywords: protection, groundwater, surface water, pollution, industrial plants

DOI:10.7862/rb.2016.195

Przestano do redakcji: 15.08.2016 $r$.

Przyjęto do druku: 30.11.2016 r. 